1 Understanding complex drivers of wildlife crime to design effective conservation

\title{
2 interventions
}

Henry Travers', Lucy J. Archer²,3, Geoffrey Mwedde ${ }^{4}$, Dilys Roe ${ }^{5}$, Julia Baker6, Andrew Plumptre ${ }^{7,8}$, Aggrey Rwetsiba ${ }^{9}$ and E.J. Milner-Gulland ${ }^{1}$

${ }^{1}$ Interdisciplinary Centre for Conservation Science, Department of Zoology, University of Oxford, Oxford, OX1 3SZ, UK.

${ }^{2}$ Formerly Department of Life Sciences, Imperial College London, Ascot, SL5 7PY, UK

${ }^{3}$ University College London, Gower Street, London, WC1E 6BT, UK.

${ }^{4}$ Wildlife Conservation Society Uganda Program, Plot 802 Kiwaffu Road, Kansanga, P. O. Box 7487, Kampala, Uganda.

${ }^{5}$ International Institute for Environment and Development

${ }^{6}$ Balfour Beatty, Biodiversity Technical Services, 5 Churchill Place, Canary Wharf, London E14 5HU

${ }^{7}$ Wildlife Conservation Society, 2300 Southern Boulevard, Bronx, NY 10460, USA.

${ }^{8}$ Conservation Science Group, Department of Zoology, Cambridge University, Pembroke Road, Cambridge, UK.

${ }^{9}$ Uganda Wildlife Authority, Plot 7 Kira Road, Kamwokya. P.O. BOX 3530, Kampala, Uganda.

\section{Corresponding author}

Dr Henry Travers

Department of Zoology, University of Oxford, Oxford, OX1 3PA, UK

Tel: +255 (0) 769587644

Email: henry.travers@zoo.ox.ac.uk

Keywords: Predictive conservation, wildlife crime, protected areas, community engagement, enforcement, bushmeat 


\section{Abstract}

6 In conservation, understanding the drivers of behavior and developing robust interventions to 7 promote behavioral change is challenging and requires a multi-faceted approach. This is 8 particularly true for efforts to address illegal wildlife use, where pervasive - and sometimes 9 simplistic - narratives often obscure complex realities. In this paper, we apply a set of novel 10 techniques in an integrated approach to investigate the drivers and prevalence of wildlife crime 11 in communities surrounding two national parks in Uganda and predict the performance of 12 potential interventions designed to tackle these crimes. Although poverty is often assumed to 13 be a key driver of wildlife crime, we show that better off households, as well as those that suffer from human wildlife conflict and those that do not receive any benefits from the parks' tourism 15 revenue-sharing, are more likely to be involved in certain types of wildlife crime, especially 16 illegal hunting. The interventions predicted to have the greatest impact on reducing local 17 participation in wildlife crime are those that aim to directly address the drivers including, 18 mitigating damage caused by wildlife and generating financial benefits for park-adjacent 19 households. This study demonstrates the power of a triangulated approach in gaining insights 20 into complex and hard-to-access behaviors, and highlights the importance of going beyond 21 single-driver narratives. 
Overexploitation of wildlife, including illegal use, is one of the greatest threats to the long-term survival of wildlife populations around the globe (Maxwell et al. 2016). Yet, as with many of the challenges currently faced in conservation, formulating an effective strategy to combat this threat is hampered by the complexity of the underlying factors that drive human behavior (Game et al. 2014). In such situations, there is a danger that conservationists rely on simple narratives that paper over the true complexities of a given context. This temptation to intervene based on weakly supported preconceptions particularly plagues efforts to reduce illegal use of wildlife and stem the flow of illegal wildlife products from within protected areas. Here conflicting narratives revolve not just around who is involved and what factors drive people to become involved (Duffy et al. 2016) but also around false dichotomies to describe possible solutions, of which enforcement vs. community engagement (Challender \& Macmillan 2014a; Challender \& Macmillan 2014b; Phelps et al. 2014) or trophy hunting vs. photo tourism (Di Minin et al. 2016) are just two examples. In the face of such competing arguments, robust interventions require an evidence-based approach in which the relative importance of different behavioral drivers is evaluated using a broad evidence base, and the likely performance of alternative interventions robustly assessed prior to their implementation.

The importance of understanding animal behavior is widely acknowledged in conservation science. However, human behavior and the factors that drive it remain woefully underappreciated (Cowling 2014). Yet, in many contexts, it is human behavior that represents the greatest threat to wildlife - no more so than in the case of wildlife crime. Effective conservation action is thus dependent on understanding and addressing the motivations behind that behavior (St John et al. 2013). Research is increasingly being conducted in this area (Mackenzie \& Harrter 2013; Nuno et al. 2013; Wilfred et al. 2017) but most studies apply a limited number of methods, without the triangulation or broad perspective needed to reflect the complexity of human behavior (von Essen et al. 2014). Similarly, while the use of predictive methods to investigate the impact of behavior change interventions has increased (Travers et al. 2011; Moro et al. 2013; Williams et al 2014; Travers et al. 2016), such approaches remain underutilized.

In this paper, we apply a multi-faceted approach to developing effective interventions to tackle wildlife crime. Our approach integrates estimates of actual behavior, qualitative and quantitative investigations of the attitudes and preferences of a range of different actors, and reported future behavior under a series of different interventions designed to address wildlife crime. Combining these different strands of investigation not only provides robust evidence upon which interventions can be developed, but also the basis for future active adaptive management through which progress can be assessed and corrective actions taken if required (Grantham et al. 2010; Fig. 1). We apply such an approach to investigate the drivers and prevalence of wildlife crime in villages surrounding Uganda's two largest national parks, Queen Elizabeth Protected Area (QEPA) and Murchison Falls Protected Area (MFPA), and examine the likely effectiveness of alternative interventions proposed to address wildlife crime within the two parks. Uganda has strict protection laws for natural resources, such that, unless the Uganda Wildlife Authority (UWA) has granted prior approval, extraction of most resources inside protected areas is illegal. Consequently, wildlife crime covers a wide range of offences from the collection of medicinal plants to hunting elephants for ivory. Hence, there is a wide variety of actors engaged in wildlife crime with a diverse set of motivations, operating in different areas (Critchlow et al. 2015), making effective policies to reduce wildlife crime challenging to develop. 
While there has been a long history of community engagement associated with Uganda's protected areas, notably around Bwindi Impenetrable National Park (Blomley et al. 2014), this has typically not received the same level of investment as law enforcement for most protected areas. Expenditure on enforcement-based interventions to combat wildlife crime accounts for a significant proportion of annual budgets at park level (Plumptre et al. 2014; Critchlow et al. 2015). Where community engagement approaches have been implemented by UWA, the focus has mostly been on outreach and education, coupled with measures to mitigate wildlife damage to crops and livestock. Efforts have also been made to increase the benefit park-adjacent communities receive from protected areas through a process of revenue sharing (whereby $20 \%$ of park entry fees are allocated to local governments to invest in development projects, such as clinics, schools and small livestock schemes; Tumusiime \& Vedeld 2012) and through formal agreements with a small number of specialized resource users (e.g. collectors of firewood or building materials) which provide for limited access to the parks. However, doubts remain as to the effectiveness of these approaches (Infield \& Namara 2011; Blomley et al. 2014, Twinamatsiko et al. 2018), in particular their ability to change behavior rather than attitudes.

Here we apply the approach described in Fig. 1 to bring greater understanding of the relative importance of different drivers of five commonly encountered wildlife crimes (firewood collection, illegal grazing, illegal fishing, subsistence hunting and commercial hunting) in the two study parks. We did this through a socio-economic survey of households living around QEPA and MFPA, which included an indirect questioning component to improve willingness to give truthful answers about sensitive behaviors (the unmatched count technique, UCT; Nuno et al. 2013). We estimate the prevalence of the five wildlife crimes and investigate the profiles of households engaged in these crimes. We couple this with two empirical approaches, scenario interviews and a discrete choice experiment, to assess the likely performance of six alternative interventions being considered by UWA to combat wildlife crime (Table 1). These included "wildlife friendly" enterprises, wildlife scouts (local volunteers who help protect against cropraiding), increased law enforcement patrol effectiveness, regulated hunting using revenuesharing fund to support human wildlife conflict (HWC) mitigation, and the removal of resource access agreements. We triangulate the findings of these empirical approaches against keyinformant interviews with active and reformed wildlife offenders and UWA staff.

\section{Methods}

The study employed a mixed methods approach, combining three survey-based instruments (a socio-economic household survey, scenario interviews and a choice experiment) with qualitative key-informant interviews and group discussions. Due to considerable linguistic diversity between the two parks, it was necessary to employ two teams of enumerators for the three survey-based methods (refer to SI for further details on our approach to control for this).

\section{Socio-Economic Household Survey}

A socio-economic household survey was conducted with 1968 households living in frontline villages, which for the purposes of this study were defined as villages either directly bordering QEPA or MFPA, or with at least $50 \%$ of village area within $3 \mathrm{~km}$ of a park boundary. Villages were stratified by district and randomly selected proportionally with the length of boundary within each district and the sample size selected to ensure an even sampling distribution around each park. Within each village, households were randomly selected from a list of households maintained by village authorities. Data collection ran between February and May 2015. The survey focused on key socio-economic variables thought to affect household involvement in wildlife crime, including household poverty, livelihood strategy, participation in resource or 
revenue sharing, experience of wildlife damage and perceptions of living close to conservation areas. The selection of these variables was informed by a review of the relevant literature from Uganda and elsewhere (Harrison et al. 2015b). Household poverty was measured using two compatible approaches: the basic necessity survey (Davies and Smith 1998) and the Ugandan multi-dimensional poverty index (UMPI; UBOS 2014a), a measure used by the Uganda Bureau of Statistics to monitor national poverty levels. Both approaches use an index calculated from household ownership of key assets and access to basic services that capture different dimensions of poverty. Items for inclusion in the basic necessity survey were generated through six participatory workshops held in park-adjacent villages.

\section{Unmatched Count Technique}

The prevalence of illegal activities among local people was investigated using an indirect questioning method, the unmatched count technique (Nuno \& St John 2015), which was included as part of the socioeconomic household survey. Under this method, respondents were shown a series of five cards, each relating to a different offence (firewood collection, grazing, fishing, subsistence hunting and commercial hunting). At the beginning of each interview, respondents were randomly allocated to either the control or treatment group. Control households were shown cards with pictures of four non-sensitive items and were asked to give the number of items relevant to them. For example, the control card relating to firewood collection had four legal sources of firewood and respondents were asked to give the number of items from which their household had obtained firewood in the past year (refer to SI for further detail regarding the experimental design of the UCT). Treatment households were shown cards containing the same items as the control cards but with the addition of one sensitive item relating to the specific offence in question. For example, the firewood treatment card contained an additional photo that represented collecting firewood from the adjacent park. The composition of each card was designed such that all cards contained one item that was expected to be relevant to nearly all respondents and one item that was expected to be relevant to none of the respondents. In this way, responses were expected to fall within the upper and lower bounds (i.e. between one and three for the control cards and between one and four for the treatment cards), thereby ensuring that it was not possible to ascertain which of the items were relevant to individual respondents.

\section{Choice Experiment}

The choice experiment was used to elicit the preferences of local people for five of the interventions under consideration (experimental constraints led to the exclusion of removing resource access agreements from the choice experiment) and was conducted with 394 people. All respondents had previously been interviewed as part of the socio-economic household survey. Each respondent was presented with six choice cards in turn and for each card asked to select one of two unlabeled alternatives they preferred. No opt out option was given. Each alternative was described by five attributes (the proportion of revenue sharing funds to be allocated to mitigating HWC, the number of wildlife scouts recruited in each village, the probability that illegal hunters would be caught, whether regulated hunting was permitted or not and average earnings from the development of wildlife friendly enterprises). Each attribute had two or three distinct levels (refer to SI for further detail on the experimental design of the choice experiment). All interviews were followed by a short debriefing session. 
159 To predict how each intervention was likely to perform if implemented, scenario interviews

160 were conducted with 119 people following the method used by Travers et al. (2016; refer to SI

161 for further detail on the experimental design of the scenario interviews). As with the choice experiment, each respondent had previously participated in the socio-economic household survey. Interview respondents were presented with a series of future scenarios, each describing one of the interventions under consideration. For each scenario, respondents were asked how they would respond. As the main indicator of behavior change, household involvement in wildlife crime, is sensitive and vulnerable to bias, three proxy indicators were selected for investigation in the scenario interviews: i) time allocation to non-sensitive, legal livelihoods, ii) the perceived fairness of each intervention and iii) the probability of providing UWA with information about illegal activity.

\section{Key Informant Interviews}

Key informant interviews were conducted with national and park level UWA staff, self-reported hunters and bushmeat traders. The aim of interviewing hunters was to collect qualitative data regarding their motivations, the methods they employ and their perceptions of the different interventions considered in the scenario interviews and choice experiment. Interviews were semi-structured and conducted with 50 active or reformed hunters in eight villages located around MFPA. The responses of five known hunters were found to be highly inconsistent and were removed from subsequent analysis. Key national and park level UWA staff were interviewed individually regarding their perceptions of the factors that drive local people to become engaged in illegal activities and which interventions they considered to be most effective at addressing wildlife crime. In addition, a two-day workshop was held in July 2015 to investigate the preferences of headquarter and park level UWA staff for interventions to combat wildlife crime.

\section{Analysis}

184 Hierarchical Bayesian regression models were used to analyze the results of the UCT, choice experiment and scenario interviews. All analysis was conducted using the package rstan, version 2.8.0 (Stan Development Team 2015a), in R, version 3.2.2 (R Core Team 2015). Weakly informative half-Cauchy prior distributions (mean $=0, \mathrm{SD}=5$ ) were assigned to predictor standard errors following the Stan reference manual (Stan Development Team 2015b) and an uninformative LKJ prior (shape factor $=1$ ) was assigned to the covariance matrix. Adequate convergence was indicated by taking Gelman-Rubin statistics with values $<=1.01$ and visual inspection of traceplots. Four chains were analyzed in parallel, with the number of burn-in iterations set to achieve time convergence. Standard deviations and credible intervals for probability estimates at the $95 \%$ level were found by calculating the probability distribution of each response state using the estimated parameter values for each post-warm up run. Analysis of the UCT was split into two models (see SI for further details). Model 1 was used to produce estimates of the mean prevalence of each of the five wildlife crimes and included interaction terms between card type (i.e. the resource in question) and a treatment dummy as the only predictor variables. Model 2 was used to investigate the drivers of illegal hunting (both subsistence and commercial) and included additional interaction terms between card type, the treatment dummy and household socio-economic characteristics as predictor variables. 


\section{Prevalence and drivers of wildlife crime}

203 We estimated the proportion of households across the two study sites that had engaged in the 204 five wildlife crimes at least once in the previous year (Fig. 2a, SI Table SI.1). These estimates 205 highlight the significant difference in the prevalence of the five wildlife crimes, ranging from $20611 \%(95 \%$ credible interval (CI): $0.03,0.19)$ of households for firewood collection to $42 \%$ (95\%CI: 0.32, 0.51) commercial hunting. They also show that the two crimes expected to have the greatest impact on wildlife (subsistence and commercial hunting) are the most prevalent among households living around MFPA and QEPA.

One of the most pervasive narratives associated with wildlife crime is that people hunt because they are poor and the potential earnings, particularly for high value species such as elephants or pangolins, are too great to ignore (Duffy et al 2016). However, our findings suggest that, for our study area, this narrative is too simplistic. Contrary to the expected relationship, poorer households were significantly less likely to illegally hunt than better off households (Fig. 2b, SI Table SI.2). Better off households in the sample had levels of wealth that put them in the middle class bracket nationally. Of the two possible explanations for this result (that households are more likely to hunt because they are better off or that they have become better off through hunting), the latter is supported by the findings of interviews conducted with known hunters. People who hunt for at least 15 days per month reported earnings ranging between US\$120500 per month, which is significantly greater than average household income in Uganda (UBOS 2014b).

The findings of the hunter interviews suggest that a lack of alternative employment options may be a more important driver than material poverty. The need to earn money was cited as the primary motivation to hunt by 39 of the 42 interviewed hunters asked, with several claiming that no alternative means of earning money was available to them, particularly during the dry season. This leads some people to hunt to meet specific needs, such as medical bills or school fees, while for others hunting is the primary income source. In contrast, providing meat for domestic consumption was only cited as the primary motivation to hunt by two of the 42 interviewed hunters. The interviews with hunters also suggested that achieving higher social status, which is accorded only to a few senior hunters in each village, was not a significant motivation for most.

In addition to the potential financial benefits, households that had reported suffering from HWC were $65 \%$ more likely to hunt commercially and $80 \%$ more likely to hunt for subsistence than those who had not (Fig. 2b). Similarly, households that felt they had not benefited from revenue sharing were $27 \%$ more likely to hunt commercially and $36 \%$ more likely to hunt for subsistence (Fig. 2b) than those that had not. These results are important, as they suggest that how local people perceive the costs and benefits of living near protected areas is directly correlated with their behavior. It also shows that how people perceive benefits to be distributed may be more important than the reality of the situation as, in many cases, people were found to be unaware of local development projects had been funded by revenue sharing. If people perceive benefits to be distributed unfairly, negative behaviors may develop that might otherwise not have been present (Harrison et al. 2015a).

Another factor that may influence involvement in wildlife crime is the likelihood of being caught and the severity of penalties (Keane et al. 2008). Key informant interviews conducted with known hunters suggested that the threat of ranger patrols was not a sufficient deterrent to 
bring about behavior change. The individual rate of encounters with patrols (ranging from seeing rangers inside the park to being chased or direct ranger interactions) reported by hunters was approximately 1 in every 5 incursions into the park, whereas the reported detention rate was only 1 in every 500-1000 incursions. Hunters also suggested that the penalties issued, if arrested, were not a deterrent. The average sentence for the 13 interviewed hunters who had been previously arrested was three months in prison and a US\$120 fine (equivalent to the expected earnings from just eight incursions). Despite reports of fatal shootings or hunters going missing inside the park, hunters use these low detention rates and limited consequences of arrest to justify their belief that the benefits of hunting outweigh the risks.

\section{Stakeholder preferences for anti-wildlife crime interventions}

256

257

258

259

260

261

262

263

264

265

266

267

268

269

270

271

272

273

274

275

276

277

278

279

280

281

\section{2}

283

284

285

286

287

288

289

290

While preferences alone are not always a true indicator for how people behave, they are an important consideration in the selection and design of programs aiming to change behavior ( $\mathrm{St}$ John et al. 2010). The results of the discrete choice experiment reveal the preferences of local people, measured on a scale ranging from -1 (the least preferred option) to 1 (the most preferred option), for five interventions (Table 2). At MFPA, the most preferred option was the introduction of wildlife friendly enterprises (mean preference (pref) $=-0.49$; 95\%CI: 0.19, 0.83), closely followed by wildlife scouts. The preferences of people living around QEPA were notably different, with mitigation for HWC the most preferred intervention (pref $=-1.00$; 95\%CI: $0.60,1.45)$. This is particularly striking, as people living around MFPA expressed no preference for mitigation for HWC, except through wildlife scouts. The least preferred intervention, with negative preferences at both sites, was regulated hunting. This may be slightly surprising given the high proportion of households estimated to be hunt illegally, but was explained in debriefings by an overall distrust that such a scheme could be managed sustainably or equitably and by the fact that it had no financial benefit, as all offtake would be meant for home consumption. The only exception to this was for people who were already members of resource user groups, who expressed neither preference nor aversion for regulated hunting at either MFPA (pref=-0.01; 95\%CI: $-0.18,0.15$ ) or QEPA (pref $=-0.05$; 95\%CI: -0.08 , $0.20)$. More surprising was the mild support found at both sites for increased effectiveness of law enforcement, which runs counter to the common assumption that local people are opposed to ranger patrols.

For UWA staff from both parks, the preferred anti-wildlife crime intervention options were elicited through a separately held workshop. These were: i) increasing the effectiveness of law enforcement though ranger patrols, intelligence gathering and raising awareness among local magistrates, ii) wildlife friendly enterprises and iii) mitigating HWC. Encouragingly, the most preferred interventions match those of local people expressed through the choice experiment, although the order of preference differs, with UWA staff prioritizing law enforcement.

\section{Predicted effectiveness of interventions in reducing wildlife crime}

The results of the scenario interviews suggest that wildlife friendly enterprises were likely to be the most effective means of increasing the percentage of people who would allocate more time to pursuing legal activities at both MFPA (87\%; 95\%CI: 50\%, 100\%); Fig. 3a, SI Table SI.3) and QEPA (64\%; 95\%CI: 16\%, 97\%). For the households that reported suffering from HWC (one of the categories of household most likely to be involved in wildlife crime), wildlife friendly enterprises, wildlife scouts and mitigating HWC were all found to be highly effective at encouraging people to spend more time pursuing legal livelihoods at both sites. This shows that, although the response to these interventions may differ between the two parks, three of the 
interventions considered are predicted to have a significant impact on the behavior of the people most likely to be involved in illegal hunting.

With respect to the perceived fairness of the interventions considered, wildlife friendly enterprises, HWC mitigation and wildlife scouts were all considered either 'very fair' or 'fair', with no difference observed between the two sites (Fig. 3b, SI Table SI.4). Wildlife friendly enterprises again performed best, with a higher probability of being considered 'very fair' than both HWC mitigation (99.7\% of model runs) and wildlife scouts (100\% of model runs). Although withdrawing resource access agreements was generally found to be fair or very fair, only $7 \%$ of people who already belonged to resource user groups considered this to be fair or very fair. Conversely, while only $33 \%$ of non-members of resource groups found regulated hunting to be fair or very fair, group members widely perceived this to be a fair intervention ( $88 \%$ fair or very fair). These findings suggest that, although local perceptions of certain conservation interventions are widely positive, perceptions of other interventions will vary according to a group's experience of similar interventions or the expected impact on their livelihoods.

The interventions predicted to be most likely to encourage communities to provide intelligence and information about illegal activities to UWA were, again, wildlife friendly enterprises, mitigating HWC and wildlife scouts (Fig. 3c, SI Table SI.5). For these three interventions, the percentage of people who felt they would be more likely to provide information was $82 \%$ (95\%CI: 68\%, 97\%), 79\% (95\%CI: 63\%, 95\%)and 57\% (95\%CI: 39\%, 75\%) respectively. A small percentage of people $(29 \%$; $95 \% \mathrm{CI}$ : 10\%, 45\%) were also more likely to provide information under regulated hunting, while removing resource access had no effect. These results suggest that community engagement approaches can be effective not just in reducing opportunity for households to engage in wildlife crime, but also in improving relations with park authorities so that people feel more inclined to provide assistance to law enforcement efforts.

\section{$\underline{\text { Discussion }}$}

The demand for evidence-based conservation interventions (Sutherland et al. 2004; Pullin \& Knight 2005; Ferraro \& Pattanyak 2006; Cook et al. 2010) requires sufficient evidence on which to base decisions. Where commonly held but untested narratives feed into decisionmaking, underlying assumptions about behavioral drivers should be interrogated. In Uganda, as elsewhere (Duffy et al. 2016), there is a widespread belief that poverty is a leading cause of wildlife crime. However, our findings suggest that the situation is more nuanced than this, with better off households more likely hunt illegally than poorer households. While this suggests that immediate need may not currently be a primary driver, opportunities to earn money remain limited in many rural communities. Hence, poverty may have been the original driver of hunting for households that have since become better off through hunting. Involvement in wildlife crime offers an additional income stream, which in some cases is highly lucrative, such that those involved have a competitive advantage over households that choose not to be. A focus on poorer households may therefore miss the households that have the greatest impact on wildlife. Instead, a broader focus on the creation of income-generating opportunities, particularly during seasons in which agricultural labor demands are low, may be more effective. It is important, however, that efforts to provide such opportunities learn from the lessons of past programs that were often based on weak assumptions, such as the substitutability of livelihoods (Wright et al. 2016).

It is also important to understand local people's perceptions of conservation (Bennett 2016) and the role these can play in determining behavior and intervention outcomes. 
Our finding that people who perceive that their wellbeing is suffering due to HWC, or do not feel like they are benefiting from revenue sharing, are more likely to be engaged in illegal hunting suggests that local attitudes towards park authorities (and conservation more widely) focus of UWA's community engagement, are unlikely to be sufficient to elicit behavior change. Where investment has been made in incentive-based projects, these have often not been sufficiently linked to conservation outcomes or the specific behaviors that pose a threat to wildlife (Harrison et al 2015a). Encouragingly, our results predict that people who suffer HWC - precisely those whose behavior we aim to influence - are more likely than others to change their behavior if interventions that directly address these concerns are implemented. This result reflects our overall finding that interventions that address the underlying drivers of wildlife crime are most likely to result in positive outcomes. This argues against blanket application of particular "in vogue" approaches across a range of circumstances, but rather for targeting specific interventions to address specific drivers of wildlife crime. At MFPA, our findings suggest that wildlife friendly enterprises, which enhance the income-generating potential of agricultural products (thereby reducing the need to use wildlife crime as an alternative source of income), may be most effective. At QEPA, increasing investment in long-term, effective mitigation of HWC may be a more important step to improving people's perceptions of conservation and their relations with park authorities. Currently, despite public commitment to tackling HWC, some within UWA consider that local people should be responsible for preventing the damage caused by wildlife. Although this corresponds to research that has shown that locally administered mitigation activities tend to be more effective (Hedges et al. 2010), it ignores the costs incurred by local people (both through damage to crops, livestock and people and in implementing mitigation measures). Providing greater and more consistent financial support for mitigation measures would improve the situation.

Our finding that increasing the effectiveness of law enforcement would, on average, be positively received by local people (in addition to being strongly supported by UWA staff) is encouraging because it suggests that it may be possible to change the social acceptability of wildlife crime. It also dispels the idea that law enforcement and community engagement are discrete choices, whose objectives are automatically opposed. This is supported by our finding that local reporting of illegal activities, an essential element of efforts to combat illegal trade in high value species (Linkie et al 2015; Cooney et al. 2016), is predicted to be increased through greater community engagement. This would require an improved working relationship between local people and rangers, since the provision of information is risky for informants and requires effective and timely support from law enforcement personnel (Wilkie et al. 2016), again highlighting the need for local support of law enforcement activities. A balanced approach, in which law enforcement and community engagement interventions are complementary actions, would therefore be most effective in incentivizing behavioral change.

In addition to predicting the effectiveness of conservation interventions, the feasibility of their implementation should be considered. For alternative livelihood projects, which have a history of mixed success, investment in local institutions is critical. This can take significant investment of both time and financial resources, and requires sufficient capacity within wildlife authorities. UWA's community conservation staff lack the skills, budget and manpower needed to design and support such programs. Consequently, while wildlife friendly enterprises are predicted to perform well in reducing wildlife crime, it may be some time before they can have a meaningful impact. Conversely, greater and more consistent investment in mitigating HWC should result in more immediate impacts and UWA staff are already familiar with many of the measures to be put in place. A sensible strategy may be to invest first in greater protection from HWC, both 
as a means of reducing the costs associated from living close to wildlife and improving relationships between the park staff and local communities. At the same time, UWA's community conservation staff can be trained to design, implement and monitor more complex livelihood programs. Strategic partnerships with other sectors of government (e.g. agricultural extension or social protection) could also be used to leverage greater impact from such interventions.

By taking the novel approach of integrating an investigation of the drivers of wildlife crime with a predictive assessment of the effectiveness of alternative interventions, we have identified the actions most likely to reduce illegal wildlife use at the two national parks. The recommendations derived from this research have since been incorporated into park-level action plans to address wildlife crime (Travers et al. 2017) and are currently being piloted at MFPA. This piloting process will enable greater understanding of the costing, feasibility and likely impact to be obtained. However, it is important to recognize that at a finer scale than we considered here, there are likely to be other sociological, historical and cultural factors that will affect both how people behave, and how they perceive and respond to interventions aimed at reducing wildlife crime. In the event that similar approaches to ours are implemented on a wider scale, it is important that the local context is taken into account, as illustrated by the finding that preferences for different interventions varied between QEPA and MFPA. This will be particularly true for Uganda's forested parks that are likely to have a different set of drivers from the largely savannah woodland parks included in this study (Harrison et al. 2015b). Consequently, any wider rollout should be accompanied by a process of monitoring and active adaptive management to account for changing conditions and the inherent uncertainty associated with the use of predictive approaches (Grantham et al 2010).

\section{$\underline{\text { References }}$}

Bennett NJ (2016) Using perceptions as evidence to improve conservation and environmental management. Conserv Biol 30(3):582-592.

Blomley T, et a. (2010) Development and gorillas? Assessing fifteen years of integrated conservation and development in south-western Uganda. IIED, London.

Challender DWS, MacMillan DC (2014a) Poaching is more than an enforcement problem. Conserv Lett 7(5):484-494

Challender DWS, Macmillan DC (2014b) Transforming wildlife trade interventions: reply to Phelps et al. Conserv Lett 7(5):497-49.

Cook CN, Hockings M, Carter R (Bill) (2010) Conservation in the dark? The information used to support management decisions. Front Ecol Environ 8(4):181-186.

Cooney R, et al. (2016) From Poachers to Protectors: Engaging Local Communities in Solutions to Illegal Wildlife Trade. Conserv Lett 10(3):367-374.

Cowling RM (2014) Let's Get Serious About Human Behavior and Conservation. Conserv Lett 7(3):147-148.

Critchlow R, et al. (2015) Spatiotemporal trends of illegal activities from ranger-collected data in a Ugandan national park. Conserv Biol 29(5):1458-1470. 
Davies R, Smith W (1998) The Basic Necessities Survey: the experience of ActionAid Vietnam. AcionAid, Hanoi.

Di Minin E, Leader-Williams N, Bradshaw CJA (2016) Banning Trophy Hunting Will Exacerbate Biodiversity Loss. Trends Ecol Evol 31(2):99-102.

Duffy R, St John FAV, Büscher B, Brockington D (2016) Toward a new understanding of the links between poverty and illegal wildlife hunting. Conserv Biol 30(1):14-22.

Ferraro PJ, Pattanayak SK (2006) Money for nothing? A call for empirical evaluation of biodiversity conservation investments. PLoS Biol 4(4):e105.

Game ET, Meijaard E, Sheil D, McDonald-Madden E (2014) Conservation in a Wicked Complex World; Challenges and Solutions. Conserv Lett 7(3):271-277.

Grantham HS, et al. (2010) Effective conservation planning requires learning and adaptation. Front Ecol Environ 8(8):431-437.

Harrison M, Baker J, Twinamatsiko M, Milner-Gulland EJ (2015a) Profiling unauthorized natural resource users for better targeting of conservation interventions. Conserv Biol 29(6):1636-1646.

Harrison M, Roe D, Baker J, Mwedde G, Travers H, Plumptre A, Rwetsiba A, MilnerGulland EJ (2015b) Wildlife Crime: a review of the evidence on drivers and impacts in Uganda. IIED, London.

Hedges S, et al. (2010) Reducing human-elephant conflict: do chillies help deter elephants from entering crop fields? Oryx 44(1):139.

Keane A, Jones JPG, Edwards-Jones G, Milner-Gulland EJ (2008) The sleeping policeman: understanding issues of enforcement and compliance in conservation. Anim Conserv 11(2):75-82.

Infield M, Namara A (2001) Community attitudes and behavior towards conservation: an assessment of a community conservation programme around Lake Mburo National Park, Uganda. Oryx 35(1):48-60.

Linkie M, et al. (2015) Safeguarding Sumatran tigers: evaluating effectiveness of law enforcement patrols and local informant networks. J Appl Ecol 52(4):851-860.

Mackenzie CA, Hartter J (2013) Demand and proximity: drivers of illegal forest resource extraction. Oryx 47(2):288-297.

Maxwell SL, Fuller RA, Brooks TM, Watson JEM (2016) Biodiversity: The ravages of guns, nets and bulldozers. Nature 536(7615):143-145.

Moro M, et al. (2013) An investigation using the choice experiment method into options for reducing illegal bushmeat hunting in western Serengeti. Conserv Lett 6(1):37-45. 
Nuno A, Bunnefeld N, Naiman LC, Milner-Gulland EJ (2013) A novel approach to assessing the prevalence and drivers of illegal bushmeat hunting in the serengeti. Conserv Biol 27(6):1355-65.

Nuno A, St. John FAV (2015) How to ask sensitive questions in conservation: A review of specialized questioning techniques. Biol Conserv 189:5-15.

Phelps J, Shepherd CR, Reeve R, Niissalo MA, Webb EL (2014) No easy alternatives to conservation enforcement: response to Challender and Macmillan. Conserv Lett 7(5):495-496.

Plumptre AJ, et al. (2014) Efficiently targeting resources to deter illegal activities in protected areas. J Appl Ecol 51(3):714-725.

Pullin AS, Knight TM (2005) Assessing Conservation Management's Evidence Base: a Survey of Management-Plan Compilers in the United Kingdom and Australia. Conserv Biol 19(6):1989-1996.

R Core Team (2015) R: A language and environment for statistical computing. R Foundation for Statistical Computing, Vienna, Austria.

St. John FAV, Edwards-Jones G, Gibbons JM, Jones JPG (2010) Testing novel methods for assessing rule breaking in conservation. Biol Conserv 143(4):1025-1030.

St John FAV, Keane AM, Milner-Gulland EJ (2013) Effective conservation depends upon understanding human behavior. Key Topics in Conservation Biology 2 (John Wiley \& Sons, Oxford), pp 344-361.

Stan Development Team (2015b) Stan Modeling Language Users Guide and Reference Manual, Version 2.9.0.

Stan Development Team (2015a) RStan: the R interface to Stan, Version $2.8 .0 \mathrm{http}: / / \mathrm{mc}-$ stan.org/rstan.html.

Sutherland WJ, Pullin AS, Dolman PM, Knight TM (2004) The need for evidence-based conservation. Trends Ecol Evol 19(6):305-8.

Travers H, Clements T, Keane A, Milner-Gulland EJ (2011) Incentives for cooperation: The effects of institutional controls on common pool resource extraction in Cambodia. Ecol Econ 71:151-161.

Travers H, Clements T, Milner-Gulland EJ (2016) Predicting responses to conservation interventions through scenarios: A Cambodian case study. Biol Conserv 204:403-410.

Travers H, Mwedde G, Archer L, Roe D, Plumptre A, Baker J, Rwetsiba A Milner-Gulland EJ (2017) Taking action against wildlife crime in Uganda. IIED, London.

Tumusiime D, Vedeld P (2012) False promise or false premise? Using tourism revenue sharing to promote conservation and poverty reduction in Uganda. Conserv Soc 10(1):15. 
Twinamatsiko M, Baker J, Franks P, Infield M, Oolsthom F, Roe D (2018) An overview of integrated conservation and development in Uganda. Conservation and development in Uganda, eds Sandbrook C, Cavanagh CJ, Tumusiime, DM (Routledge/Earthscan, New York and London), pp. 45-58.

UBOS (2014a) Poverty Status report 2014: structural change and poverty reduction in Uganda. Uganda Bureau of Statistics.

UBOS (2014b) National population and housing census 2014: provisional results. Uganda Bureau of Statistics.

von Essen E, Hansen HP, Nordström Källström H, Peterson MN, Peterson TR (2014) Deconstructing the Poaching Phenomenon. Br J Criminol 54(4):632-651.

Wilfred P, Milner-Gulland EJ, Travers H (2017) Attitudes to illegal behavior and conservation in western Tanzania. Oryx:1-10.

Williams SJ, Jones JPG, Annewandter R, Gibbons JM (2014) Cultivation can increase harvesting pressure on overexploited plant populations. Ecol Appl 24(8):2050-2062.

Wilkie D, Painter M (2016) Rewards and risks associated with community engagement in anti-poaching and anti-trafficking.

Wright JH, et al. (2016) Reframing the concept of alternative livelihoods. Conserv Biol 30(1):7-13. 


\section{$\underline{\text { Tables }}$}

Table 1: Intervention options considered for combatting wildlife crime at QEPA and MFPA.

\begin{tabular}{|c|c|}
\hline Intervention & Description \\
\hline $\begin{array}{l}\text { Human wildlife } \\
\text { conflict mitigation }\end{array}$ & $\begin{array}{l}50 \% \text { of revenue sharing funds would be allocated to activities } \\
\text { aimed at mitigating human wildlife conflict. }\end{array}$ \\
\hline Wildlife scouts & $\begin{array}{l}\text { Two people from each village would be employed by UWA to } \\
\text { respond to incidences of human wildlife conflict in their village. }\end{array}$ \\
\hline $\begin{array}{l}\text { Wildlife friendly } \\
\text { enterprises }\end{array}$ & $\begin{array}{l}\text { A "wildlife friendly" enterprise scheme, for which participation } \\
\text { would be dependent on signing an agreement not to be involved in } \\
\text { wildlife crime. Average earnings would be } 500,000 \text { shillings per } \\
\text { year and non-compliant households would be suspended for one } \\
\text { year. }\end{array}$ \\
\hline $\begin{array}{l}\text { Increased patrol } \\
\text { effectiveness }\end{array}$ & $\begin{array}{l}\text { The probability that illegal activities within the parks is detected } \\
\text { would be increased by a factor of } 10 \text {. }\end{array}$ \\
\hline $\begin{array}{l}\text { Removal of resource } \\
\text { access }\end{array}$ & $\begin{array}{l}\text { All formal agreements between UWA and local communities that } \\
\text { allow certain resources to be harvested from the parks would be } \\
\text { withdrawn. }\end{array}$ \\
\hline Regulated hunting & $\begin{array}{l}\text { Resource access agreements would be expanded to allow certain } \\
\text { species to be hunted using permitted methods. Only hunting for } \\
\text { home consumption would be permitted and offtake numbers and } \\
\text { zones in which hunting was permitted would be set each year. }\end{array}$ \\
\hline
\end{tabular}


Table 2: Local people's preference estimates ${ }^{1}$ for intervention options aimed at reducing wildlife crime at MFPA and QFNP. Sample $N=394$.

\begin{tabular}{|l|c|c|}
\hline \multirow{2}{*}{ Coefficient } & \multicolumn{2}{|c|}{ Posterior mean (95\% credible interval) } \\
\cline { 2 - 3 } & Murchison Falls NP & Queen Elizabeth NP \\
\hline Human wildlife conflict mitigation & $0.05(-0.23,0.34)$ & $1.0(0.60,1.45)$ \\
Wildlife scouts & $0.38(0.20,0.59)$ & $0.64(0.37,0.97$ \\
Wildlife friendly enterprises & $0.49(0.19,0.83)$ & $0.35(0.03,0.68)$ \\
Increased patrol effectiveness & $0.09(0.01,0.17)$ & $0.23(0.12,0.36)$ \\
Regulated hunting & $-0.14(-0.28,-0.02)$ & $-0.08(-0.20,0.04)$ \\
\hline
\end{tabular}

1 Relative preferences range on a possible scale from -1 (least preferred option) to +1 (most preferred option) 


\section{Figure Legends}

Figure 1: An adaptive management cycle for addressing wildlife crime in which the investigation of stakeholder attitudes and preferences, estimation of current behavior and behavioral drivers and application of predictive approaches can inform the design of interventions.

Figure 2: 2a. Estimates of the percentage of households involved in illegal activities. 2b. Marginal effect of household covariates on the percentage of households involved in subsistence and commercial hunting. Error bars show 95\% credible intervals. $N=1968$.

Figure 3: Paneled figure of three scenario interview indicators (A. time allocation; B. intervention fairness; C. probability of providing information). For each scenario (each bar), the probability of possible responses is shown. Figure $3 \mathrm{~A}$ gives the probability of responses for households that suffer/do not suffer from human wildlife conflict (HWC) in both MFPA and QEPA. Figure 3B gives the probability of responses for households with/without resource access. $\mathbf{N}=119$. 


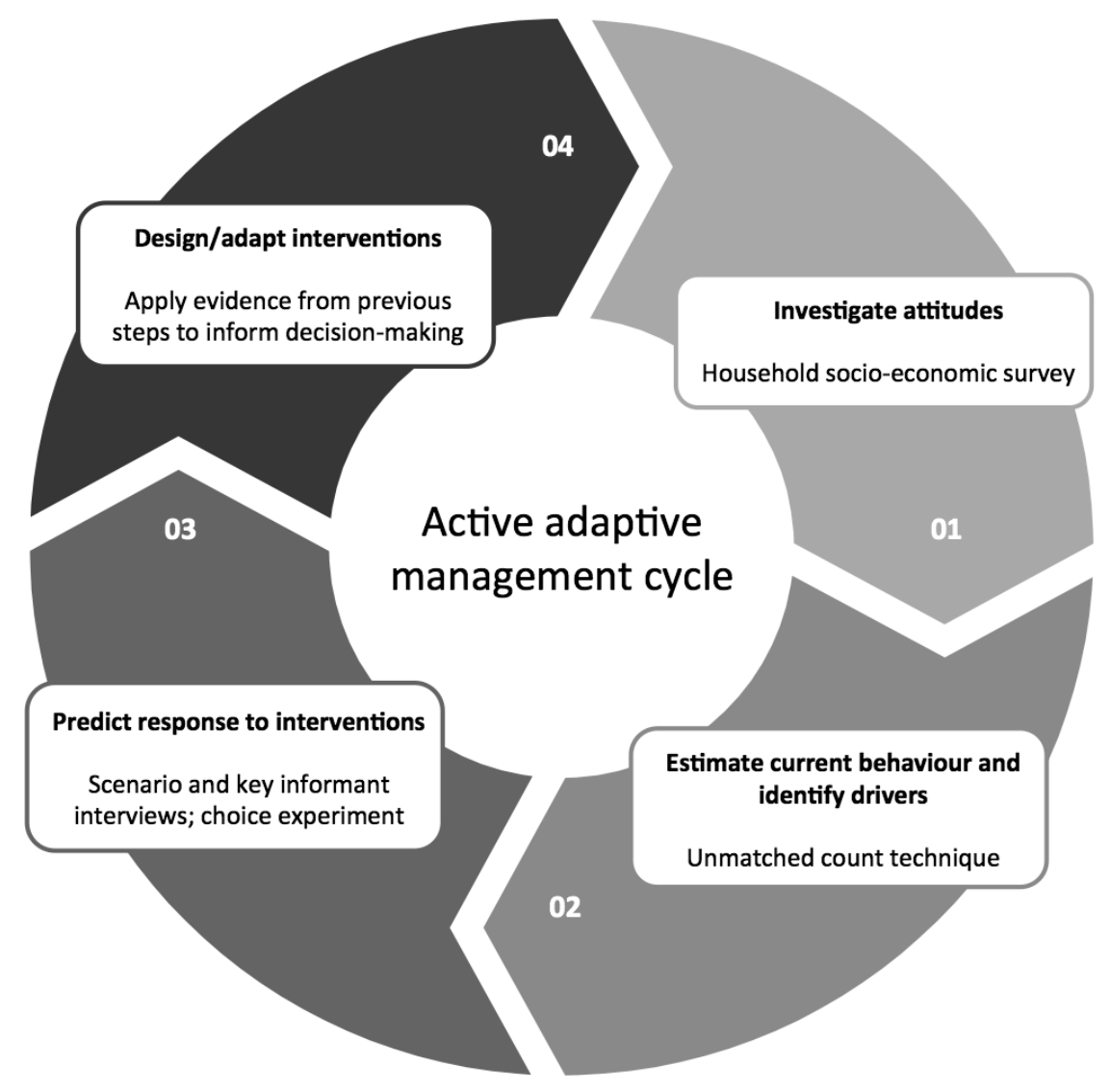

Figure 1: An adaptive management cycle for addressing wildlife crime in which the investigation of stakeholder attitudes and preferences, estimation of current behavior and behavioral drivers and application of predictive approaches can inform the design of interventions.

$2 a$.

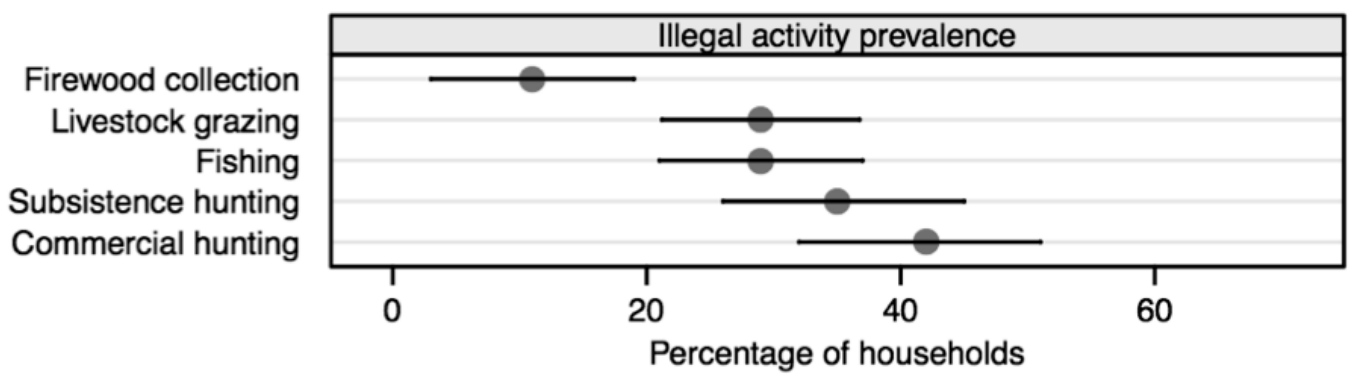

$2 \mathrm{~b}$.

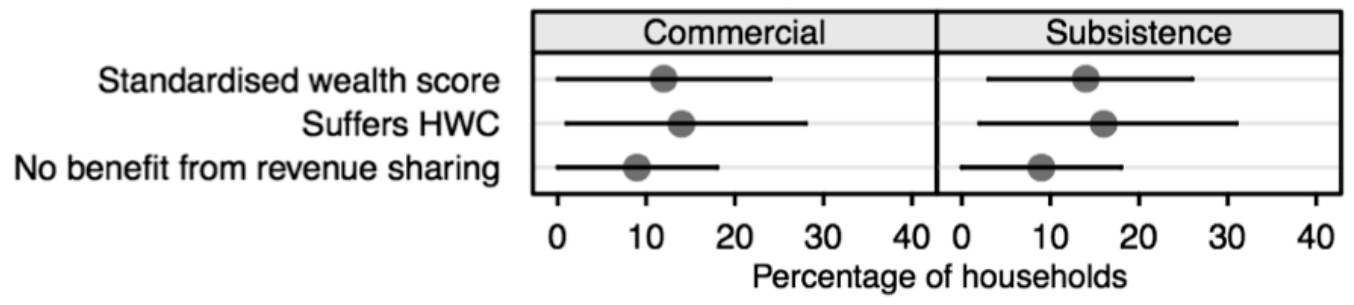

Figure 2: 2a. Estimates of the percentage of households involved in illegal activities. 2b. Marginal effect of household covariates on the percentage of households involved in subsistence and commercial hunting. Error bars show 95\% credible intervals. $\mathrm{N}=1968$. 

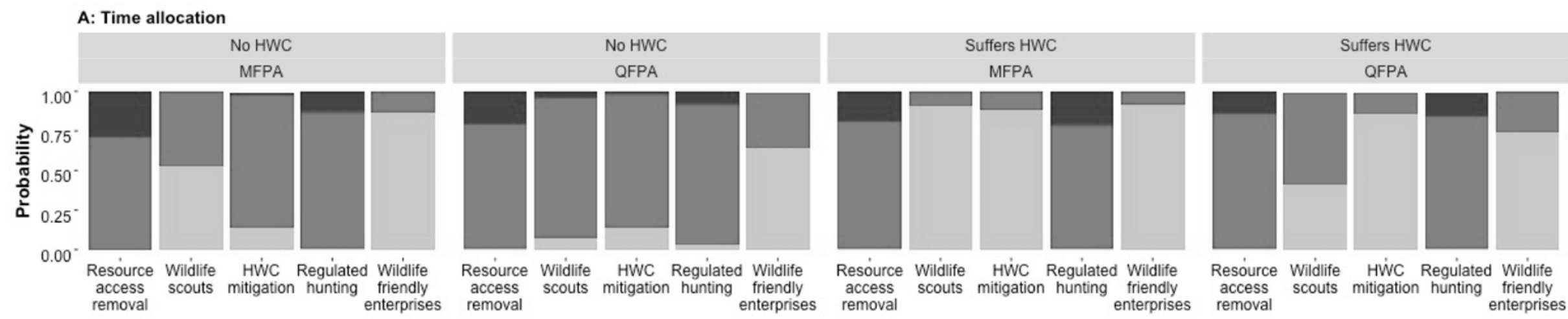

Less time for legal livelihoods

No change More time for legal livelihoods

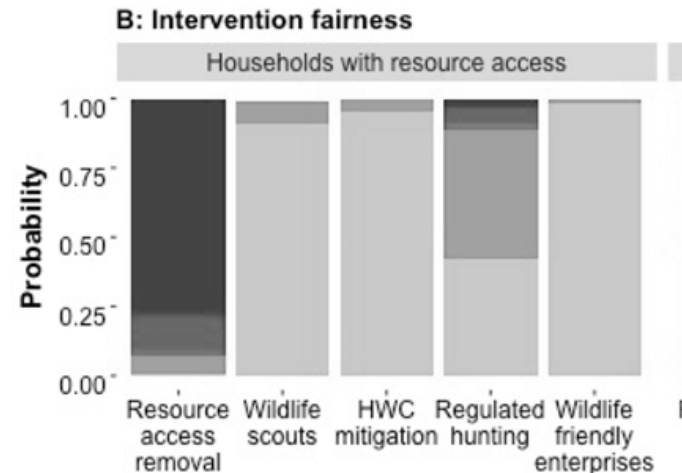

Households without resource access

C: Probability of providing information

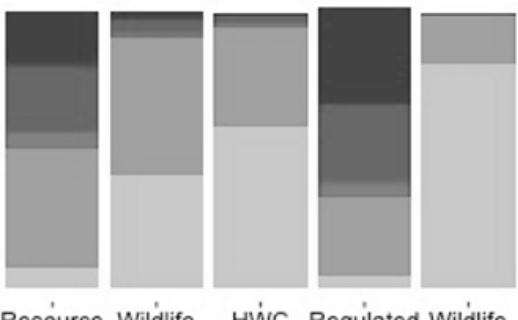

Resource Wildilife HWic Regúlated Wild́life $\begin{aligned} & \text { Resource Wildlife } \\ & \text { access }\end{aligned}$ scouts mitigation hegulated Wildlife
removal

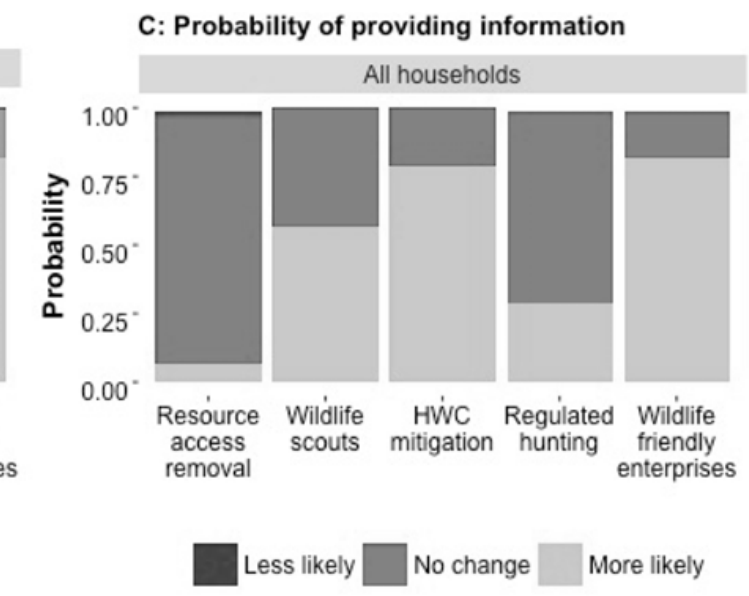

Figure 3: Paneled figure of three scenario interview indicators (A. time allocation; B. intervention fairness; C. probability of providing information). For each scenario (each bar), the probability of possible responses is shown. Figure 3A gives the probability of responses for households that suffer/do not suffer from human wildlife conflict (HWC) in both MFPA and QEPA. Figure 3B gives the probability of responses for households with/without resource access. $\mathrm{N}=119$ 